\title{
Microwave-Assisted Extraction Applied to Merlot Grapes with Contrasting Maturity Levels: Effects on Phenolic Chemistry and Wine Color
}

\author{
L. Federico Casassa ${ }^{1, * \mathbb{C}}$, Santiago E. Sari ${ }^{2}$, Esteban A. Bolcato ${ }^{2}$ and Martin L. Fanzone ${ }^{3}$ \\ 1 Wine \& Viticulture Department, California Polytechnic State University, San Luis Obispo, CA 93407, USA \\ 2 Centro de Estudios de Enología, Estación Experimental Agropecuaria Mendoza, Instituto Nacional de \\ Tecnología Agropecuaria (INTA), San Martín 3853, Luján de Cuyo, Mendoza 5507, Argentina; \\ sari.santiago@inta.gob.ar (S.E.S.); bolcato.esteban@inta.gob.ar (E.A.B.) \\ 3 Laboratorio de Aromas y Sustancias Naturales, Instituto Nacional de Tecnología Agropecuaria (INTA), \\ San Martín 3853, Luján de Cuyo, Mendoza 5507, Argentina; fanzone.martin@inta.gob.ar \\ * Correspondence: lcasassa@calpoly.edu; Tel.: +805-756-2751
}

Received: 4 January 2019; Accepted: 24 January 2019; Published: 28 January 2019

\begin{abstract}
Merlot grapes were harvested with three maturity levels (21.1, 23.1, and 25.1 Brix), and processed with or without the application of microwave-assisted extraction (MW). The detailed phenolic composition and color were followed during winemaking. The MW treatment did not affect the basic chemical composition of the wines. Upon crushing, MW caused a 211\% improvement in anthocyanins in the wines of the first harvest and an $89 \%$ improvement in the wines of the third harvest. At bottling, MW favored the formation of pyranoanthocyanins and tannin-anthocyanin dimers. Tannin extraction was not affected by MW just after application of this process, but improvements of 30,20, and 10\% on MW-treated wines of the first, second, and third harvest, respectively, were recorded at pressing. The formation of polymeric pigments during aging generally increased along with harvest date and was only favored in MW-treated wines of the first and third harvest, with preferential formation of small polymeric pigments, in accordance with enhanced anthocyanin extraction in these wines. Initial improvements of wine color upon application of MW in the wines of the first, second, and third harvest were of 275,300 , and $175 \%$, respectively. Although these differences subsided or disappeared for the wines of the second and third harvest during aging, the wines of the first harvest treated with MW retained 52\% more color than Control wines at day 150 post-crushing. Results suggest the MW treatment was more efficient in extracting and retaining phenolics and color when applied to unripe fruit.
\end{abstract}

Keywords: anthocyanins; tannins; polymeric pigments; wine color; grape maturity; microwave-assisted extraction; Merlot

\section{Introduction}

In Vitis vinifera L. grapes and their wines, grape maturity plays a key role in defining the phenolic and aromatic composition of the resulting wines [1-3]. Phenolic compounds are secondary metabolites that define critical aspects of red wine sensory composition, including color, taste, and mouthfeel sensations [4]. Phenolic compounds are non-volatile molecules synthetized through the phenylpropanoid pathway [5]. This pathway has its inception shortly after bloom [6], and continues during berry ripening, producing, among other molecules, anthocyanins, compounds responsible for wine color; tannins, compounds responsible for wine textural properties, such as astringency; and flavan-3-ols, compounds responsible for eliciting bitterness sensations in red wines [5,7]. As the relative proportion of anthocyanins (generally confined to the skins of the majority of Vitis vinifera $\mathrm{L}$. 
varieties), and tannins (located both in skins and seeds) change during ripening, winemakers usually define harvest decisions based on a complex combination of factors that include weather forecast and disease pressure, fruit basic chemistry (including Brix, $\mathrm{pH}$, and titratable acidity), and phenolic composition (including anthocyanins and tannins).

Studies in Cabernet Sauvignon, Merlot, and Tempranillo have found a direct link between grape maturity, usually defined in terms of color and phenolic composition, and wine composition [1,3,8]. This accumulated knowledge has, in turn, allowed the production of wines with specific sensory features based on harvest time. Bindon et al. (2014) [9] studied the effect of five different harvest dates, with sugar levels spanning from 20 to 26 Brix, and corresponding alcohol contents in the finished wines spanning from 12 to $15.5 \% \mathrm{v} / \mathrm{v}$. It was found that wine anthocyanins and tannins increased with harvest date, as well as an enhanced extraction of skin-derived phenolics [9]. From a sensory standpoint, later harvest dates produced wines with less green or vegetative attributes and more dark fruit attributes [1].

Because grape maturity plays such a critical role in wine composition, it is expected that the outcomes of a given winemaking technique may be different based on when the fruit is harvested. In turn, variations in ethanol due to changes in fruit maturity may have an effect in phenolic extraction as well. For example, a study based on Cabernet Sauvignon and Tempranillo grapes harvested at three different maturity levels and processed with four different maceration lengths (1, 2, 3, and 4 weeks), reported that tannin extraction in Cabernet Sauvignon was enhanced in riper fruit and more so when submitted to longer maceration times. However, fruit ripeness did not affect tannin extraction in Tempranillo wines [8]. Contrastingly, Casassa et al. (2013) [3] investigated the effect of grape maturity and extended maceration (30 days) in Merlot grapes and their corresponding wines, and alcohol contents produced from fruit with two contrasting maturity levels, namely 20.3 and 24.9 Brix, were also compensated during maceration via chaptalization and water addition. It was found that riper fruit produced wines that were fruitier and with fuller mouthfeel, whereas chaptalization of unripe fruit shifted the sensory profile towards that of riper fruit. It was also found that the outcomes of extended maceration, particularly in regards to tannin extraction, were independent of fruit maturity [3]. These discrepancies suggest that variety, fruit maturity and the specific winemaking technique employed all affect the phenolic composition, color, and sensory properties in the finished wines.

Among the bevy of innovative winemaking techniques introduced in the wine industry since the early 90's, thermomaceration (also known as thermovinification) and flash-expansion (also known as flash-détente), are based on heating the crushed grapes before fermentation to favor phenolic extraction. In effect, if phenolic extraction into wine is accepted as a combination of both dissolutive and diffusive processes, application of heat to freshly crushed grapes may boost mass-transfer processes, thus, favoring diffusion in the case of anthocyanins [10]. In addition, temperature may also increase the permeability of cell wall membranes, thereby favoring dissolution [11].

A series of studies using flash-détente applied to Grenache and Carignan grapes, whereby the heated must $\left(95^{\circ} \mathrm{C}\right)$ is released into a vacuum causing cell disorganization, found that this technique increased the extraction of polysaccharides [12] as well as wine phenolics by a factor of 1.2 to 2 [13]. Another study compared the effects of thermomaceration at $60{ }^{\circ} \mathrm{C}$ applied to País (also known as Mission) and Lachryma Christi grapes to that of the use of pectolytic enzymes, commonly used as extraction aids in winemaking. Expectedly, thermomaceration favored phenolic extraction and increased antioxidant capacity in both varieties relative to the enzyme treatment, which was attributed to an increased diffusion coefficient [14].

Given the previous findings, winemakers typically restrict the use of thermomaceration or flash-détente to lesser quality grapes that may be, for instance, unripe (thereby lacking phenolic maturity), or affected by fungal diseases. The reasoning behind is that the extractability of phenolic compounds of sensory relevance is lower in unripe fruit or compromised versus fully ripe fruit, and as such, positive improvements in the finished wines could be more effectively achieved by thermally treating unripe grapes. 
One problem associated with the use and application of thermomaceration or flash-détente, however, is that both techniques are onerous, requiring steam generators (i.e., large input of water), heat exchangers, and dedicated pumps installed on-site. Conversely, microwave-assisted extraction (MW) is a novel technique that has been recently studied at experimental scale [15]. Industrial-scale MW has been in operation in the food industry over a period of several decades now, but its use in winemaking it is innovative and appears attractive. During MW, the dipolar nature of water molecules caused them to align with the direction of an oscillating electric field created by MW. This alignment occurs at a rate of million times per second and causes internal friction of molecules resulting in volumetric heating [16]. Importantly, MW requires no water input. A preliminary study of the application of MW to Cabernet Sauvignon, Merlot, and Syrah grapes was conducted to explore a potential differential effect of MW on different grapes varieties. This study found an interaction between variety and the MW treatment in that the MW treatment failed to increase color in Cabernet Sauvignon and Merlot, but it did so in Syrah [17]. Another study on Pinot noir, a variety particularly deficient in skin-derived phenolics, reported that MW produced a four-fold increase in tannin concentration, additionally causing a decrease in the native grape yeast-derived populations [18].

In the present work, we examined the effect of MW applied to three batches of Merlot fruit from the same vineyard block harvested at three maturity levels. This included unripe fruit (to simulate fruit harvested earlier due to disease pressure), properly ripe fruit (to simulate production of regular table red wine), and overripe fruit (more representative of current standard winemaking conditions). At each harvest point, triplicate fermentations of untreated musts (i.e., Control wines), and MW-treated musts were followed in terms of their color properties as well as specific phenolic composition throughout winemaking. Herein we present a detailed report of the effect of harvest maturity, MW-assisted extraction and their combination thereof on the chromatic and phenolic composition of Merlot wines. This study aimed to establish the most suitable grape maturity level that may optimize the application of MW for winemaking purposes.

\section{Materials and Methods}

\subsection{Grapes}

Own-rooted Merlot grapes (Vitis vinifera L.) were obtained from a commercial vineyard located in Luján de Cuyo, Mendoza, Argentina ( $\left.33^{\circ} 00^{\prime} \mathrm{S}, 68^{\circ} 51^{\prime} \mathrm{W}\right)$. The fruit was sequentially harvested targeting 21, 23, and 25 Brix on February 3, February 27, and March 29, 2015, respectively. At each harvest, a total of $150 \mathrm{~kg}$ of fruit were manually harvested to $18-\mathrm{kg}$ plastic boxes for a total of $360 \mathrm{~kg}$. For the grape basic analysis, four independent samples, each of 30 berries, were taken at each harvest analyzed for basic fruit chemistry, including Brix (Atago, Tokyo, Japan), pH (Orion model 701-A, Thermo Scientific, Waltham, MA, USA), and titratable acidity, which was determined manually by titration with $0.1 \mathrm{~N} \mathrm{NaOH}$ and expressed as $\mathrm{g} / \mathrm{L}$ of tartaric acid [19] (Table 1).

\subsection{Winemaking and Application of Microwave-Assisted Extraction}

Upon each harvest, grapes were transported to the experimental winery of INTA. Upon reception, grapes were first crushed and destemmed (Metal Liniers model MTL 12, Mendoza, Argentina), and the musts placed into 20-L food-grade plastic fermentors. The experimental design consisted of two winemaking treatments applied to the fruit of each harvest, namely Control (not microwaved) wines, and microwaved-assisted extraction (MW) wines, with each winemaking treatment replicated three times $(n=3)$, and the MW treatment applied inmediately after crushing. Control wines were produced with a standard $\mathrm{SO}_{2}$ addition of $50 \mathrm{mg} / \mathrm{L}$, and a maceration length of 14 days at $24.5 \pm 2.5^{\circ} \mathrm{C}$; cap management consisted of two daily punch downs (morning and afternoon, $1 \mathrm{~min}$ each). For the MW treatments, a commercially available household microwave oven was used. Musts were microwaved at 1200 Watts for $10 \mathrm{~min}(\sim 400$ Watts $/ \mathrm{kg})$, reaching an average temperature of approximately $40{ }^{\circ} \mathrm{C}$. This working temperature was attained in the whole mass and was calculated in 
each batch as the average of three independent temperature measurements throughout the mass of must being microwaved $(\sim 3 \mathrm{~kg}$ ) (exact average temperature attained \pm standard deviation: $\left.40.16 \pm 3.81^{\circ} \mathrm{C}, n=270\right)$. Five batches of MW musts were added per each fermentor for a total of $\sim 15 \mathrm{~kg}$ of musts/fermentor. Upon cooling, MW wines were added with $50 \mathrm{mg} / \mathrm{L}$ of $\mathrm{SO}_{2}$ and produced with a maceration length of 14 days, following the same cap management regime applied to Control wines. All the fermentors were inoculated approximately $8 \mathrm{~h}$ after crushing with a commercial yeast (EC-1118; Lallemand Inc., Copenhagen, Denmark) at a rate of $0.3 \mathrm{~g} / \mathrm{L}$. After maceration was completed, free run wines were collected into $20 \mathrm{~L}$ glass carboys fitted with airlocks. Malolactic fermentation (MLF) was induced with a commercial Oenococcus oeni culture (VP-41, Lallemand Inc., Copenhagen, Denmark). Malic acid composition was followed monthly, and MLF was stopped when there was no significant consumption of malic acid in the wines within a 30-day period. After this, the wines were racked off the lees, adjusted to $30 \mathrm{mg} / \mathrm{L}$ of free $\mathrm{SO}_{2}$, and stored at $1{ }^{\circ} \mathrm{C}$ for 45 days to allow tartaric stabilization. After this period, the wines were racked and brought to room temperature for $48 \mathrm{~h}$. Before bottling, free $\mathrm{SO}_{2}$ was adjusted to $0.5 \mathrm{mg} / \mathrm{L}$ of molecular $\mathrm{SO}_{2}$. The bottles were then stored horizontally in a cellar $\left(12 \pm 1^{\circ} \mathrm{C}\right)$ until needed.

\subsection{Wine Basic Analysis}

Alcohol content, residual sugars, glucose + fructose, tartaric, citric, lactic and acetic acid, titratable acidity, and glycerol content were measured using a FOSS Wine-Scan (FT120) rapid-scanning infrared Fourier-transform spectrometer (FOSS, Hillerod, Denmark). Malic acid was determined enzymatically (Vintessential Laboratories, Victoria, Australia). pH was measured with an Orion model 701-A (Thermo Scientific, Waltham, MA, USA). Titratable acidity was determined manually by titration with $0.1 \mathrm{~N}$ $\mathrm{NaOH}$ and expressed as $\mathrm{g} / \mathrm{L}$ of tartaric acid [19].

\subsection{Spectrophotometric Analysis of the Wines}

Must and wine samples were filtered through 0.22-mm filters (Fisher Scientific, Fair Lawn, NJ, USA) before analysis. Spectrophotometric measurements were carried out with a Perkin-Elmer Lambda 25 UV-visible spectrophotometer (PerkinElmer, Hartford, CT, USA). Wine color was calculated as the summation of the absorbances at 420,520 , and $620 \mathrm{~nm}$ and hue as the ratio of absorbances at 420 and $520 \mathrm{~nm}$ [20]. Tannins in the wines were analyzed by protein precipitation [21]. Anthocyanins, small polymeric pigments (SPP), large polymeric pigments (LPP), and total polymeric pigments (SPP $+\mathrm{LPP})$ were measured as previously described [21].

\subsection{HPLC-DAD-Mass Spectrometry (MS) Analysis of the Wines}

The detailed pigment composition of each of the 18 wines was measured at bottling. Identification and MS confirmation of anthocyanins were performed by HPLC-DAD coupled with electrospray ionization (ESI)-MS as described [22]. The chromatographic system employed was a Perkin-Elmer Series 200 HPLC-DAD equipped with a quaternary pump and an autosampler (PerkinElmer, Hartford, CT, USA). Two $\mathrm{mL}$ of wine was filtered through a $0.45-\mu \mathrm{m}$ pore size nylon membrane (Fisher Scientific, Fair Lawn, NJ, USA), and a 100- $\mu$ L aliquot was injected onto the column. Separation was performed on a reversed-phase Chromolith Performance C18 column (100 mm × $4.6 \mathrm{~mm}$ i.d., $2 \mu \mathrm{m}$; Merck (Darmstadt, Germany)) protected with a Chromolith guard cartridge $(10 \mathrm{~mm} \times 4.6 \mathrm{~mm})$ at $25^{\circ} \mathrm{C}$. A gradient consisting of solvent A (water/formic acid, 90:10, $v / v$ ) and solvent B (acetonitrile) was applied at a flow rate of $1.1 \mathrm{~mL} / \mathrm{min}$ from 0 to $22 \mathrm{~min}$ and $1.5 \mathrm{~mL} / \mathrm{min}$ from 22 to $35 \mathrm{~min}$ as follows: 96 to $85 \%$ A from 0 to $12 \mathrm{~min}, 85$ to $85 \%$ A from 12 to $22 \mathrm{~min}, 85$ to $70 \%$ A from 22 to $35 \mathrm{~min}$; followed by a final wash with $100 \%$ methanol and re-equilibration of the column. DAD was performed from 210 to $600 \mathrm{~nm}$, and the quantification was carried out using peak area measurements at $520 \mathrm{~nm}$. In both years, monomeric anthocyanins and anthocyanin derivatives were quantified using malvidin-3-O-glucoside chloride as the standard (Extrasynthèse, Genay, France) and a standard calibration curve for each year $\left(R^{2}=0.98\right.$ and 0.99 for 2014 and 2015, respectively). 


\subsection{Data Analysis}

The basic composition of the fruit at harvest was analyzed by a one-way analysis of variance (ANOVA). The phenolic, anthocyanin, and chromatic compositions of the wines were analyzed by a one-way ANOVA. When appropriate, a two-way ANOVA separating the effects of the grape maturity and winemaking treatments, and their interaction, was also performed. Fisher's least significant difference (LSD) test was used as a post-hoc comparison of means in all cases with a 5\% level for rejection of the null hypothesis. The detailed phenolic, anthocyanin, and pigment composition was further analyzed by simultaneous Student's $t$-tests comparing Control and MW wines of each harvest separately, establishing a 5\% level for rejection of the null hypothesis. Data were analyzed with XLSTAT v. 2015 (Addinsoft, Paris, France).

\section{Results and Discussion}

\subsection{Basic Chemical Composition of the Grapes}

Merlot fruit was harvested in three separate events to capture a wide range of fruit chemistry based on harvest time. In turn, these chemical changes at the fruit level were expected to impact the outcome of MW-assisted extraction on their respective wines. Overall, the three harvests spanned almost two months, from early February to late March. There were 24 days from the first to the second harvest, and 30 days between the second and third harvest (Table 1). The first harvest yielded fruit considered unripe for standard winemaking conditions for red wine production. The second harvest produced fruit considered ripe whereas the third harvest, while slightly overripe, was also considered fully ripe for current winemaking standards. As intended, as maturity progressed from the first to the third harvest, Brix and $\mathrm{pH}$ increased whereas titratable acidity decreased.

Table 1. Harvest date and basic chemical composition of the fruit of each treatment immediately after harvest. Averages followed by the standard error of the mean (SEM) $(n=6)$.

\begin{tabular}{ccccc}
\hline Harvest Treatment & Harvest Date & Brix & pH & Titratable Acidity $(\mathbf{g} / \mathrm{L})$ \\
\hline First harvest & 3-Feb & $21.16 \pm 0.08 \mathrm{a}^{\mathrm{a}}$ & $3.24 \pm 0.18 \mathrm{a}$ & $8.18 \pm 0.15 \mathrm{c}$ \\
\hline Second harvest & 27-Feb & $23.14 \pm 0.09 \mathrm{~b}$ & $3.48 \pm 0.01 \mathrm{~b}$ & $5.05 \pm 0.04 \mathrm{~b}$ \\
\hline Third harvest & 29-Mar & $25.16 \pm 0.08 \mathrm{c}$ & $3.75 \pm 0.01 \mathrm{c}$ & $4.61 \pm 0.04 \mathrm{a}$ \\
\hline
\end{tabular}

${ }^{a}$ Means followed by different letters within the same column indicate significant differences for Fisher's least significant difference (LSD) test and $p<0.05$.

\subsection{Basic Chemical Composition of the Finished Wines}

Table 2 reports the basic chemical composition of the 18 wines produced as a result of the combination of harvesting Merlot fruit at three maturity levels and applying MW, in addition to Control (i.e., untreated) treatments (three harvest treatments $\times$ two winemaking treatments $\times$ triplicate fermentations). Table 2 shows a two-way ANOVA presenting $p$-values for the separate effects of harvest time, the two winemaking treatments, and their interaction. The harvest treatment clearly impacted the basic chemistry of the wines, whereas the winemaking treatments did not. Differences in alcohol content between harvest treatments reflected differences previously observed as a function of grape maturity in Brix levels (Table 1). The $\mathrm{pH}$ of the wines also mirrored fruit $\mathrm{pH}$ showing the expecting trend of wine $\mathrm{pH}$ being higher than fruit $\mathrm{pH}$, although, for the wines of the third harvest, wine $\mathrm{pH}$ was lower than fruit $\mathrm{pH}$. This discrepancy for the wines of the third harvest was probably due to an error at the moment of sampling. Winemakers often report that the actual fruit $\mathrm{pH}$ can only be effectively assessed once the crushed fruit, that is must, has soaked in contact with the solids for, at least, $24 \mathrm{~h}$ post-crushing. It is possible that in the third harvest fruit, not all the acids were released upon crushing, therefore leading to lower than expected titratable acidity and higher than expected $\mathrm{pH}$. Only alcohol content was affected as a result of the winemaking treatments, with MW-treated wines of the second harvest showing higher levels relative to the corresponding Control wines from this harvest. 
The acid composition of the wines, broadly defined by titratable acidity and encompassing tartaric, citric, malic, and lactic acid, as well as volatile acids (acetic acid) was generally not affected by the winemaking treatments. However, the harvest treatment did have an impact on these parameters. Of note was lower tartaric acid levels in the wines of the second harvest and lower citric acid levels in the wines of the third harvest. Malolactic fermentation was not completed in both Control and MW wines of the second harvest, as evidenced by the residual malic acid content in the vicinity of 0.90 to $0.93 \mathrm{~g} / \mathrm{L}$ malic acid. Malolactic fermentation was only partially completed in the wines of the other two harvests.

Regarding the carbohydrate composition of the wines, both the content of Glu+Fru, and the residual sugar content, were generally higher in the wines of the third harvest. However, differences in residual sugars with the wines of the first and second harvest are unlikely to be of chemical and/or sensory relevance.

Mirroring trends observed for Brix (in the fruit) and alcohol content (in the finished wines), the glycerol content of the wines, although unaffected by the winemaking techniques, increased progressively from the first to the third harvest, with the wines of the first harvest showing the lowest glycerol content and the wines of the third harvest showing the highest, with wines of the second harvest placing in between. This result is consistent with previous reports indicating increasing concentrations of glycerol in wines made from grapes of increasing sugar levels $[9,23]$. 
Table 2. Two-way analysis of variance (ANOVA) of the basic chemical composition of Merlot wines of the different harvest and microwave treatments at bottling. Averages followed by the standard error of the mean (SEM) $(n=3)$.

\begin{tabular}{|c|c|c|c|c|c|c|c|c|c|c|c|c|}
\hline $\begin{array}{c}\text { Harvest } \\
\text { Treatment }\end{array}$ & $\begin{array}{c}\text { Microwave } \\
\text { Treatment }\end{array}$ & $\begin{array}{c}\text { Alcohol \% } \\
(v / v)\end{array}$ & $\mathrm{pH}$ & $\begin{array}{c}\text { Titratable } \\
\text { Acidity }(\mathrm{g} / \mathrm{L})\end{array}$ & $\begin{array}{c}\text { Tartaric Acid } \\
(\mathrm{g} / \mathrm{L})\end{array}$ & Citric Acid (g/L) & Malic Acid (g/L) & Lactic Acid (g/L) & Acetic Acid (g/L) & $\begin{array}{c}\text { Glucose }+ \\
\text { Fructose }(g / L)\end{array}$ & $\begin{array}{c}\text { Residual } \\
\text { Sugars }(\mathrm{g} / \mathrm{L})\end{array}$ & Glycerol (g/L) \\
\hline \multirow{2}{*}{ First harvest } & Control & $12.41 \pm 0.06 \mathrm{a}^{\mathrm{a}}$ & $3.43 \pm 0.09 \mathrm{a}$ & $5.57 \pm 0.03 \mathrm{~b}$ & $2.32 \pm 0.03 \mathrm{~d}$ & $0.31 \pm 0.05 \mathrm{~b}$ & $0.50 \pm 0.06 \mathrm{a}$ & $1.53 \pm 0.03 \mathrm{bc}$ & $0.92 \pm 0.01 \mathrm{~b}$ & $0.60 \pm 0.28 \mathrm{a}$ & $0.87 \pm 0.21 \mathrm{a}$ & $9.50 \pm 0.01 \mathrm{a}$ \\
\hline & MW & $12.42 \pm 0.08 \mathrm{a}$ & $3.46 \pm 0.07 \mathrm{a}$ & $5.68 \pm 0.12 \mathrm{~b}$ & $2.22 \pm 0.05 \mathrm{~cd}$ & $0.27 \pm 0.08 \mathrm{~b}$ & $0.57 \pm 0.03 \mathrm{a}$ & $1.51 \pm 0.07 \mathrm{bc}$ & $0.93 \pm 0.03 \mathrm{~b}$ & $0.98 \pm 0.41 \mathrm{a}$ & $1.26 \pm 0.66 \mathrm{a}$ & $9.87 \pm 0.26 \mathrm{ab}$ \\
\hline \multirow{2}{*}{$\begin{array}{l}\text { Second } \\
\text { harvest }\end{array}$} & Control & $13.50 \pm 0.06 \mathrm{~b}$ & $3.60 \pm 0.07 \mathrm{~cd}$ & $5.53 \pm 0.17 \mathrm{~b}$ & $1.73 \pm 0.10 \mathrm{a}$ & $0.37 \pm 0.05 \mathrm{~b}$ & $0.93 \pm 0.06 \mathrm{~b}$ & $1.49 \pm 0.06 \mathrm{bc}$ & $0.93 \pm 0.03 \mathrm{~b}$ & $0.27 \pm 0.14 \mathrm{a}$ & $0.73 \pm 0.35 \mathrm{a}$ & $10.43 \pm 0.07 \mathrm{bc}$ \\
\hline & MW & $13.76 \pm 0.09 \mathrm{c}$ & $3.62 \pm 0.02 \mathrm{~d}$ & $5.50 \pm 0.06 \mathrm{~b}$ & $1.60 \pm 0.05 \mathrm{a}$ & $0.41 \pm 0.08 \mathrm{~b}$ & $0.90 \pm 0.06 \mathrm{~b}$ & $1.54 \pm 0.11 \mathrm{c}$ & $0.92 \pm 0.01 \mathrm{~b}$ & $0.47 \pm 0.06 \mathrm{a}$ & $0.53 \pm 0.27 \mathrm{a}$ & $10.41 \pm 0.15 \mathrm{bc}$ \\
\hline \multirow{2}{*}{ Third harvest } & Control & $15.11 \pm 0.06 \mathrm{~d}$ & $3.58 \pm 0.09 \mathrm{bc}$ & $5.08 \pm 0.12 \mathrm{a}$ & $2.11 \pm 0.06 \mathrm{bc}$ & $0.05 \pm 0.02 \mathrm{a}$ & $0.50 \pm 0.11 \mathrm{a}$ & $1.33 \pm 0.03 \mathrm{ab}$ & $0.81 \pm 0.01 \mathrm{a}$ & $1.93 \pm 0.35 \mathrm{~b}$ & $2.81 \pm 0.11 \mathrm{~b}$ & $10.56 \pm 0.17 \mathrm{c}$ \\
\hline \multirow{2}{*}{\multicolumn{13}{|c|}{$2.03 \pm 0.04 \mathrm{D}$ ANOVA factors and interactions }} \\
\hline & & & & & & & & & & & & \\
\hline \multicolumn{2}{|c|}{ Harvest treatment $(\mathrm{H})$} & $<0.0001^{b}$ & $<0.0001$ & 0.001 & $<0.0001$ & $<0.0001$ & $<0.0001$ & 0.002 & 0.001 & $<0.0001$ & $<0.0001$ & 0.001 \\
\hline \multicolumn{2}{|c|}{ Microwave treatment (MW) } & 0.025 & 0.830 & 0.612 & 0.034 & 0.827 & 0.831 & 0.476 & 0.116 & 0.387 & 0.535 & 0.229 \\
\hline \multicolumn{2}{|c|}{$\mathrm{H} \times \mathrm{M}$ interaction } & 0.194 & 0.056 & 0.805 & 0.842 & 0.745 & 0.555 & 0.317 & 0.092 & 0.874 & 0.658 & 0.575 \\
\hline
\end{tabular}

${ }^{\mathrm{a}}$ Means followed by different letters within the same column indicate significant differences for Fisher's LSD test and $p<0.05$. ${ }^{\mathrm{b}}$ Significant $p$ values $(p<0.05)$ are shown in bold fonts. 


\subsection{Phenolic and Chromatic Composition of the Wines}

Figure 1 shows the extraction and evolution of selected phenolic classes and color during the length of winemaking, through malolactic fermentation, and after a short aging period, spanning a total of 150 days after crush. One of the main goals of the present study was to follow the effect of MW-assisted extraction throughout aging. This is because other similar extraction techniques based on heating crushed grapes, including thermomaceration and flash-détente, have been reported to produce a rapid increase in phenolic compounds, which tends to dissipate shortly after alcoholic fermentation [24] or during aging [25]. Additionally, Figure 2 presents the achieved improvements in phenolic compounds and color, when applicable, on a relative basis both at pressing and after 150 days post-crushing. The chromatic and phenolic composition of Control wines was considered as a baseline to establish these relative percentages of extraction upon MW treatment presented in Figure 2.

The most noticeable effect of MW was the fast increase in the wines' anthocyanin content upon applying this treatment to the musts of the different harvests. For example, in the case of unripe fruit, the freshly crushed must of Control wines had $180 \mathrm{mg} / \mathrm{L}$ of anthocyanins, whereas MW caused a quick extraction, amounting to $560 \mathrm{mg} / \mathrm{L}$, that is, a $211 \%$ improvement in anthocyanin content. An equally enhancing effect on anthocyanin extraction upon crushing was observed in MW musts of the second harvest. However, in the case of the ripest fruit at 25.1 Brix, the application of MW only increased anthocyanins by $89 \%$ relative to Control wines upon crushing. These results suggest that MW favored anthocyanin extraction early during winemaking in the case of unripe fruit, but this effect diminished when MW was applied to fully ripe fruit. Ripening of Vitis vinifera L. grapes encompasses complex physiological and biochemical processes, whereby skin cell walls and vacuoles undergo progressive degradation and cells become increasingly disorganized as ripening progresses, thereby, favoring the extraction of vacuolar components, such as anthocyanins and tannins [26]. Ripening also causes de-pectination and de-esterification of the grape berry cell walls, which further phenolic extractability into wine [27]. The fruit of the third harvest was fully ripe, both from a commercial and technical viewpoint. Thus, it is possible that phenolic extractability was naturally high in this fully ripe fruit, with further de-pectination of cell walls occurring during fermentation. Consequently, applying MW to this fruit caused little improvement. In fact, Figure 1 suggests that, indeed, anthocyanins were easily extractable in the fully ripe fruit, as these wines were generally higher in anthocyanins than the wines from the first and second harvest throughout winemaking. Figure 2 confirms that both at pressing, and to a lesser extent after 150 days post-crushing, anthocyanin extraction was improved more in the wines of the first harvest than in the wines of the second or third harvest.

Tannins are polymers of monomeric flavan-3-ols units and are located in both skins and seeds. Although seed- and skin-derived tannins differ in their concentration and composition, tannins are broadly defined by their ability to bind and precipitate proteins [28]. This biochemical fact explains both why seed and skin tannins can elicit astringency (which occurs as a result of the precipitation of salivary proline-rich proteins in human saliva by wine tannins) and why tannins can be measured by precipitating them with a standardized protein such as bovine serum albumin (BSA) [21]. The present study reports this fraction of wine tannins, that is, the vast majority of them that precipitate with proteins and are able to elicit astringency. In the measurement performed just upon crushing, the application of MW caused little effect on the initial tannin extraction in the case of the wines of the first and second harvest. Effects on the wines of both harvests were seen after day 6 (first harvest) and after day 17 (second harvest). The lack of early tannin extraction in these wines may be due to the source from which the bulk of the tannin material was extracted from during maceration. Skin tannins are vacuolar compounds that are relatively easier to extract in the earlier stages of maceration [29]. However, on a berry mass basis, skin tannins are less abundant than seed tannins for most Vitis vinifera $\mathrm{L}$. varieties [30]. Seed tannins are confined in thin-walled cells below the seed cuticle [5]. As a result, the extraction of seed tannins into wine is more difficult and progresses at a slower rate relative to that of skin tannins. Because red wines are produced by allowing the contact with solids for a relatively prolonged period of time, seed-derived tannins account for the majority of tannins extracted into 
wine, particularly when extended maceration is favored [31,32]. In the present study, wines were allowed a 14-day maceration period, but it is not possible to assert the origin of the tannins extracted into these wines. A previous study on the application of another thermal technique, flash-détente, to red wines, showed that this technique favored the extraction of skin-derived tannins over that of seed-derived tannins [13]. However, the precise underlying mechanisms behind MW-assisted extraction are unknown, and, thus, the relative extractions rates achieved by MW may differ from those achieved by flash-détente or thermonaceration.

In the case of the fruit of the third harvest, their respective wines were generally higher in tannins, more so in the case of MW-treated wines. As this fruit was slightly overripe, it is possible that skin and seed tannin extractability was also higher, thereby explaining both the early increase and the long-term positive effect on wine tannin content. Another possibility is the enhancing role of ethanol on tannin extraction in the case of overripe fruit, which generated higher alcohol levels. Overall, tannin extraction upon MW treatment applied to unripe fruit increased by $30 \%$ at pressing, but only improvements of 20 and $10 \%$ were seen for the wines made from fruit of the second and third harvest, respectively (Figure 2).

Total phenolics are measured upon reaction with iron-chloride, with $\mathrm{Fe}^{3+}$ reacting with all phenolics containing vicinal dihydroxyls, but not with monohydroxylated phenols and anthocyanins [33]. Therefore, the measurement of total phenolics does include tannins, but also flavan-3-ols and flavonols. At day 0 and upon crushing, MW treated musts of the first harvested saw a $250 \%$ increase in total phenolics relative to their respective Control wines. Improvements of lesser magnitude upon application of MW were seen in the case of the fruit of the second and third harvest. At pressing, improvements or around 34\% in total phenolics were recorded in MW-treated wines of the first harvest, whereas these improvements were of 20 and $12 \%$ for the MW-treated wines of the second and third harvest, respectively (Figure 2). The maximum levels of total phenolics were achieved in the last sampling point at day 150 post-crushing, with equivalent levels in wines made from unripe and fully ripe fruit in the case of MW-treated wines. At day 150 post-crush, MW-treated wines showed significantly higher levels of total phenolics than Control wines irrespective of fruit maturity at harvest.

Total polymeric pigments encompass the summation of small polymeric pigments (SPP), which do not precipitate proteins, and large polymeric pigments (LPP), which they do. SPP are composed of low-molecular weight pigments, including pyranoanthocyanins and flavan-3-ol-anthocyanin acetaldehyde-mediated adducts [34]. LPP are covalent adducts between tannins and anthocyanins of relatively high molecular weight, which can elicit astringency, but also confer long-term color stability [34]. For simplicity, Figure 1 reports the evolution of total polymeric pigments, that is, SPP + LPP, throughout maceration and early aging of the full set of wines.

Polymeric pigment formation was minimally or not affected at all by the MW treatment in the case of the wines from the first and second harvest. However, application of the MW treatment in the wines of the third harvest produced an initially higher formation of polymeric pigments. During aging, polymeric pigment formation was favored in MW treated wines of only the first and third harvest. In effect, polymeric pigment formation was unaffected by MW in the wines of the second harvest. In the case of wines made from unripe (first harvest) or fully ripe (third harvest) fruit, higher polymeric pigment content may be explained by higher tannin extraction in these wines. In the wines of the second harvest, conversely, tannin extraction upon MW treatment was only marginally favored. It has been shown that LPP formation is favored in conditions of relatively higher availability of tannins [31]. This was certainly the case of the wines of the first harvest, and, secondarily, that of the wines of the third harvest as well. 


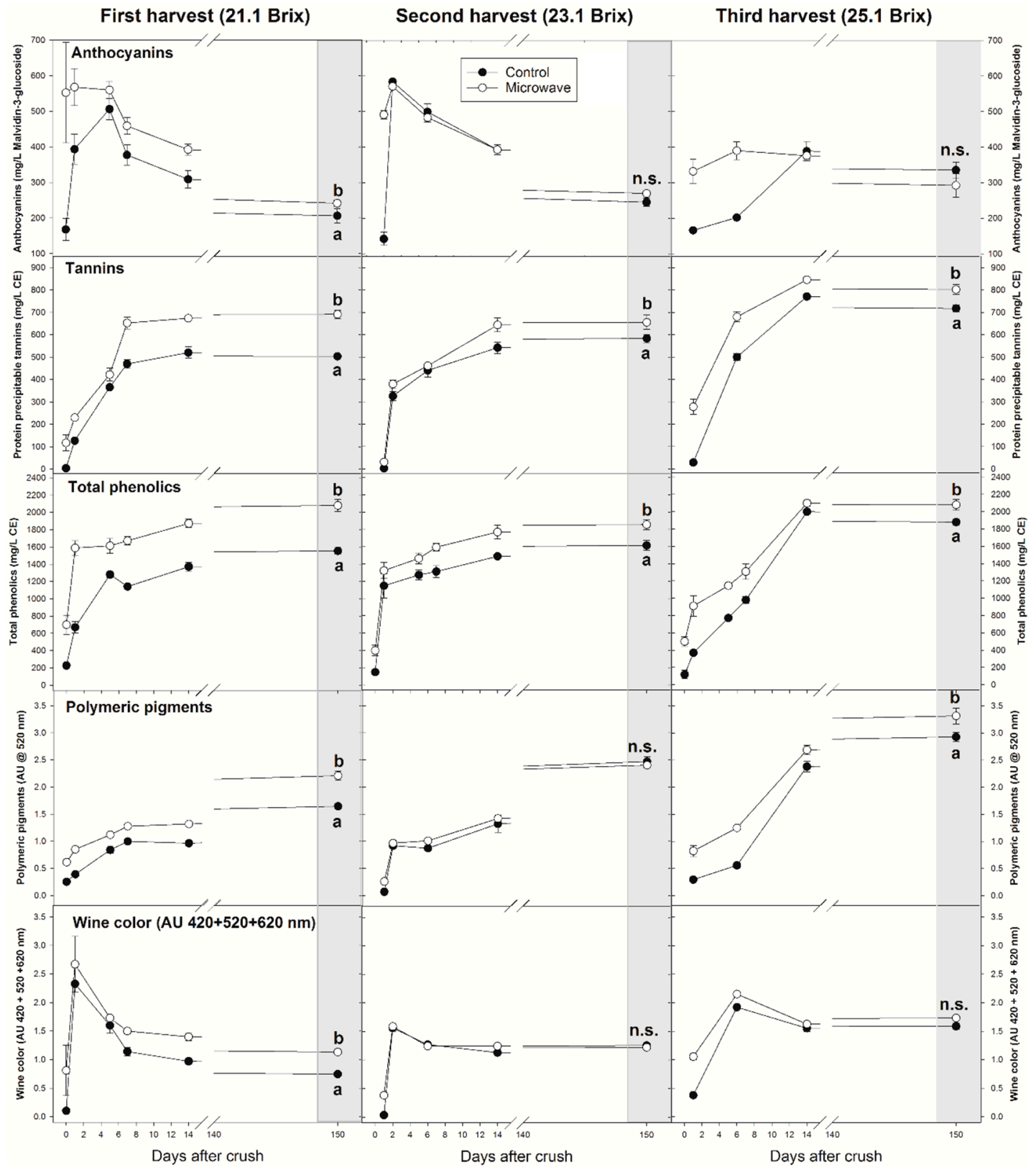

Figure 1. Evolution of anthocyanins, tannins, total phenolics, polymeric pigments and wine color in Merlot wines made from fruit harvested with three maturity levels and processed without ("Control") and with microwave-assisted extraction ("Microwave"). Different letters at day 150 post-crush between treatments made from fruit the same maturity level indicate significant differences for Student's $t$-tests and $p<0.05$. CE: catechin equivalents; AU: absorbance units. n.s.: not significant.

It was also observed that anthocyanin extraction increased upon MW treatment in the wines made from unripe fruit. At pressing, in accordance with the observed improved anthocyanin extraction, MW treated wines of the first harvest showed a $48 \%$ improvement in SPP. Improvements of much lesser magnitude in SPP were observed for the wines of the second and third harvest. Improvements in LPP upon application of MW were of a relatively lower magnitude to those observed for SPP, and they became even negative in the case of wines of the second harvest treated with MW (Figure 2). Overall, these results suggest that the MW treatment preferentially favored the formation of polymeric pigments in unripe fruit and this improvement hinged upon enhanced extraction of anthocyanins. Small polymeric pigments generally correlate with initial higher content of free anthocyanins [2]. This explains the favored formation of SPP over LPP in the MW treated wines of the first harvest. 
This finding further provides support to the early statement that MW treatment favored the extraction of anthocyanins (but not that of seed tannins) in unripe fruit and, thus, eventually favored the formation of SPP over LPP.

Notably, when all the three harvests were considered, the polymeric content of the wines increased progressively along with the ripeness of the fruit from which they were made of. In other words, the polymeric pigment content was higher in the wines made from fully ripe fruit at 25.1 Brix. A study in Syrah in which fruit was harvested at 21, 23, and 25 Brix also reported a higher concentration of $\mathrm{SO}_{2}$-resistant pigments (equivalent to polymeric pigments), in wines made from fruit harvested at 23 and 25 Brix [35]. Similar trends were reported by Bindon and colleagues in Cabernet Sauvignon, whereby riper fruit produced wines with a higher concentration of $\mathrm{SO}_{2}$-resistant pigments relative to unripe fruit, which the authors attributed to higher tannin content in the wines made from riper fruit [9].

Wine color, herein determined as the summation of absorbances at $420 \mathrm{~nm}$ (yellow hues), $520 \mathrm{~nm}$ (red hues), and $620 \mathrm{~nm}$ (blue hues) was followed during winemaking (Figure 1). Hue (420 nm/520 nm) was also determined, and it is presented as a percentage increase or decrease relative to Control wines (Figure 2). These color parameters are routinely used by wineries and are referred to as the "Glories color indexes" [20]. Initial color improvements as a result of the application of the MW treatment in the fruit from the three harvests were of higher magnitude in the case of the fruit of the second harvest (23.1 Brix) (300\% initial improvement) than in unripe fruit (21.1 Brix) (275\%), and fully ripe fruit (25.1 Brix) (175\%). However, in the wines of the second harvest treated with MW, this initial difference disappeared shortly after the onset of alcoholic fermentation and remained equivalent with the color measured in Control wines throughout winemaking. This was also the case of wines of the third harvest wherein initial improvements in wine color of MW-treated wines decreased shortly after pressing and completely converged with Control wines by day 150 post-crushing. In the case of unripe fruit, however, initial differences in favor of MW-treated wines were maintained during winemaking, in coincidence with previously reported improvements in anthocyanins, tannins, total phenolics, and polymeric pigments in these wines. Wine color improvements in MW-treated wines of the first harvest amounted to $45 \%$ at pressing and $52 \%$ at day 150 post-crushing. Furthermore, hue decreased upon application of MW in these wines, indicating these wines had more bluish and less yellow hue in their color composition, a sign of slower color evolution relative to Control wines (Figure 2). As mentioned above, improvements of wine color in MW-treated wines of the second and third harvest were only marginal at pressing and disappeared completely or even turned negative by day 150 post-crushing. Accordingly, the hue values were generally higher in MW-treated wines of the second and third harvest relative to Control wines.

In summary, phenolic content and color increases in wines made from unripe fruit treated with MW ranged from 23 to $48 \%$ at pressing and from 18 to 50\% after 150 days post-crushing. These improvements were particularly noticeable in the case of wine color (Figure 2). Improvements of lesser magnitude on phenolic content and color were recorded in the case of MW-assisted extraction applied to fruit of the second and third harvest.

A closer analysis of Figures 1 and 2 suggest a harvest treatment $\times$ winemaking treatment interaction wherein for most phenolic and color parameters the effect of the MW treatment yielded better results when applied to unripe fruit. In other words, the outcomes of the MW treatment seemed contingent upon grape maturity.

To explore this hypothesis, the phenolic and chromatic composition of the wines were analyzed by a two-way ANOVA keeping the separate effects of the harvest treatment, the winemaking treatments, and their interaction, both at pressing and after 150 days post-crushing (Tables S1 and S2, respectively). Apart from the anthocyanin content of the wines at pressing, the remaining phenolic and chromatic parameters were affected by the harvest treatments at pressing and at day 150 post-crushing. This result is not surprising, as several reports exist on the effect of harvest date on red wine phenolic composition and color $[3,9,35]$. The application of MW also affected the phenolic and chromatic composition of the 
wines, but this was more evident at day 150 post-crushing (Table S2). This result indicates that the effect of the MW treatment, unlike that of thermomaceration or flash-détente, is relatively long-lasting.

Interestingly, analysis of the harvest treatment $\times$ winemaking treatment interaction at pressing only indicated a significant interaction for anthocyanins (Table S1); the remaining phenolic and chromatic parameters being affected similarly by the MW treatments irrespective of grape maturity. However, at day 150 post-crushing, LPP, total polymeric pigments, tannins, and total phenolics all showed significant harvest treatment $\times$ winemaking treatment interactions. This suggests that the long-term effect of MW did depend upon harvest time. That is that MW-assisted extraction applied to unripe fruit produced positive and long-lasting effects on the phenolic and chromatic composition of these wines. Since the most critical changes in phenolics and color are relatively confined to maceration and early aging, including the period between the end of alcoholic fermentation and that of malolactic fermentation [4], the results herein presented provide a valid snapshot of the short-term evolution of phenolics and color of these wines.

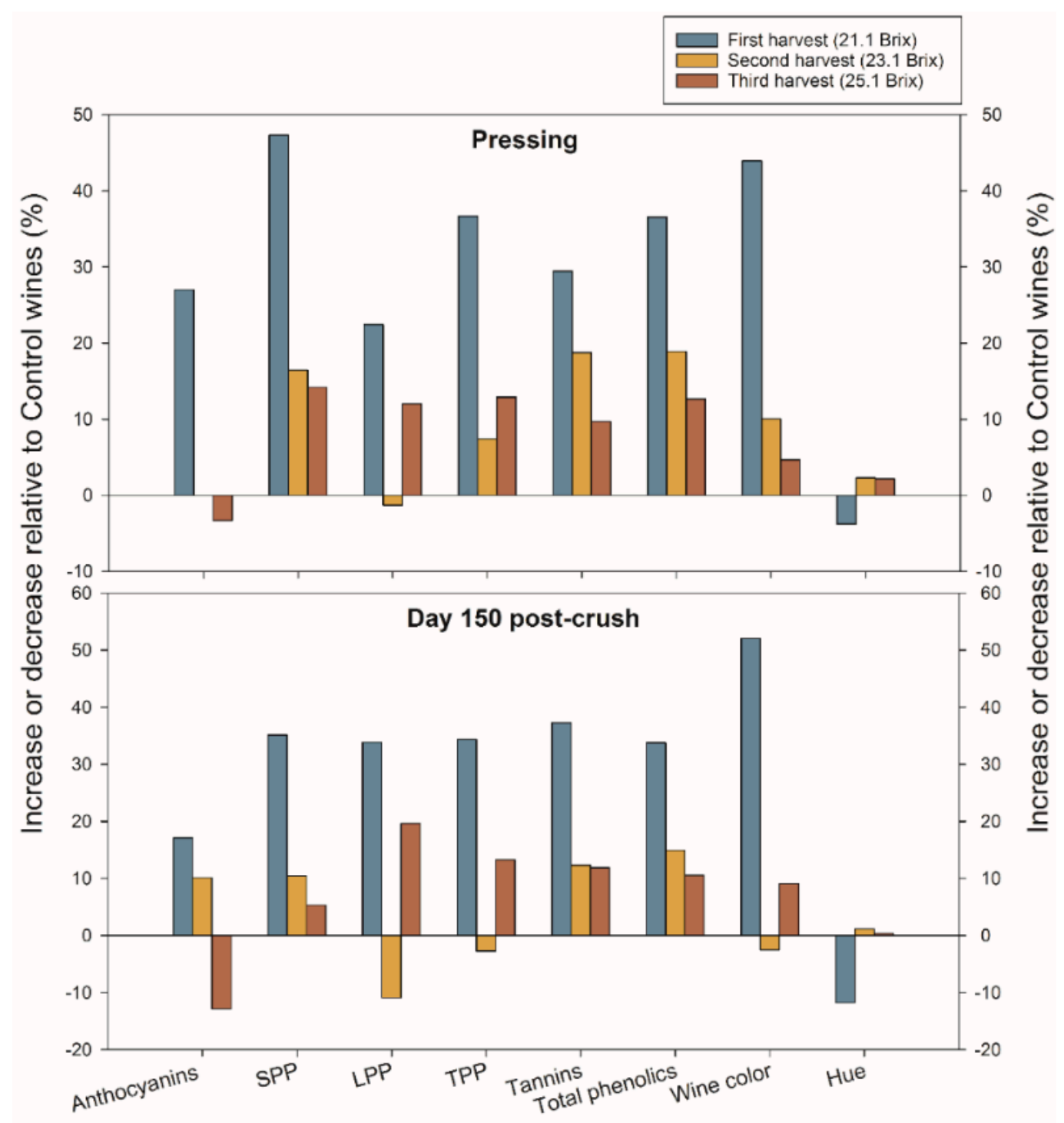

Color and phenolic parameters

Figure 2. Percentages of increase/decrease of color and phenolic parameters in Merlot wines produced with MW-assisted extraction relative to Control wines at pressing (day 14) and day 150 post-crushing. SPP: small polymeric pigments; LPP: large polymeric pigments; TPP: total polymeric pigments; wine color (AU $420 \mathrm{~nm}+520 \mathrm{~nm}+620 \mathrm{~nm})$; hue (AU $420 \mathrm{~nm} / 520 \mathrm{~nm})$. 


\subsection{Detailed Anthocyanin and Anthocyanin-Derived Pigment Composition of the Wines}

Anthocyanins and anthocyanin-derived pigments were measured after bottling by HPLC-DAD and peak identity was confirmed by mass spectroscopy (Table S3). A total of 26 anthocyanin and anthocyanin-derived pigments were identified in these Merlot wines. To facilitate the interpretation of the results, pigments were grouped as glycosides (i.e., monoglucosylated anthocyanins, including delphinidin-, cyanidin-, petunidin-, peonidin-, and malvidin-3-glucosides); acetylated (i.e., acylated anthocyanin monoglucosides, with the acyl moiety being acetic acid); coumaroylated (i.e., acylated anthocyanin monoglucosides, with the acyl moiety being $p$-coumaric acid); pyranoanthocyanins; tannin-anthocyanin dimers of direct condensation or mediated by acetaldehyde; and total pigments (i.e., the overall summation of all pigmented molecules quantified) (Figure 3). Figure 3 also presents the results of a one-way ANOVA considering all the harvest and winemaking treatments together. The concentration of each of these pigment families increased concurrently with fruit ripeness, that is, higher concentrations of each pigment families were generally found in the wines made from the riper fruit at 25.1 Brix. In the wines made from less ripe fruit, that is, 21.1 and 23.1 Brix, the MW treatment enhanced anthocyanin and anthocyanin-derived pigment contents, but this trend was not seen in the case of the wines of the third harvest. To confirm these observations, a series of Student's $t$-tests were carried out comparing the Control and MW treatments of each harvest individually. In the wines of the first harvest, MW increased the total pigment content of the treated wines by $19 \%$ relative to Control wines $(p=0.031)$, as well as that of pyranoanthocyanins $(p=0.006)$ and of anthocyanin-tannin dimers $(p=0.008)$. In the wines of the second harvest, this same increase in MW-treated wines was of $4 \%$ relative to Control wines, but was not statistically significant $(p=0.319)$. No differences were found between Control and MW-treated wines for the remaining pigment families. Likewise, no differences between Control and MW wines were found for any of the pigment families in the wines of the third harvest. These results are consistent with previous trends observed for tannins, total phenolics, and wine color whereby enhancing effects of the MW treatment were observed in the wines made from unripe fruit.

Interestingly, the MW treatment caused a positive effect in the content of pyranoanthocyanins and anthocyanin-tannin dimers in the wines of the first harvest. Pyranoanthocyanins are anthocyanin-derived pigments formed by reaction of monomeric anthocyanins with acetaldehyde, acetoacetic acid, pyruvic acid and other carbonyl compounds [36]. Anthocyanin-tannin dimers are formed via covalent reactions between anthocyanins and tannins and can be mediated by acetaldehyde [37]. While both pyrantoanthocyanins and anthocyanin-tannin dimers provide stable color, they only accounted for 10 and $3 \%$ on a concentration basis, respectively, of the total pigment content of the wines of the first harvest. Furthermore, both the results of the one-way ANOVA and independent Student's $t$-tests confirmed that, irrespective of fruit maturity, MW did not alter the extraction of monoglucosylated and acylated (acetyladed + coumaroylated) anthocyanins, which were quantitatively the major pigment families in these wines. This implies that MW generally favored anthocyanin extraction in unripe fruit but did not favor the extraction and retention of any major pigments over others. Finally, it is worth mentioning that this work did not determine the anthocyanin content of the fruit. This analysis would have allowed gauging the effectiveness of the MW treatment on anthocyanin extraction and retention into wine as a function of fruit maturity. Further work considering the initial fruit phenolic composition and the efficiency of MW in extracting specific phenolic compounds is currently underway. 


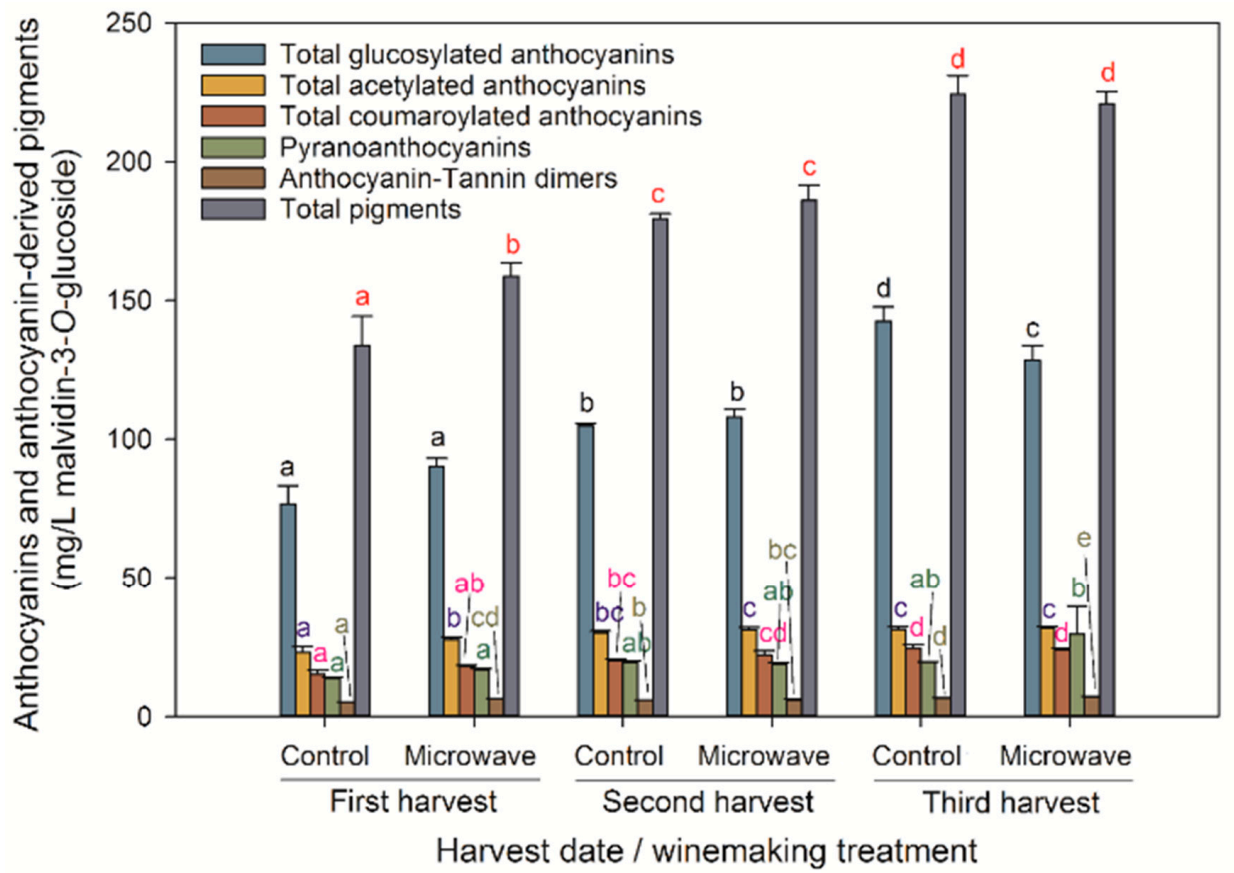

Figure 3. Detailed anthocyanin composition of Merlot wines made from fruit harvested with three maturity levels and processed without ("Control") and with microwave-assisted extraction ("Microwave") at bottling. Different letters for a given pigment group within treatments indicate significant differences for Fisher's least significant difference (LSD) and $p<0.05$. To facilitate comprehension, letters bearing the same color are associated with one specific pigment group.

\section{Conclusions}

In this work, unripe, ripe, and fully ripe Merlot grapes were harvested and made into wine prior application of MW-assisted extraction. Untreated Control wines were also produced, with winemaking procedures being kept consistent within harvest dates and throughout winemaking.

Results suggest that the MW treatment produced positive improvements on anthocyanins, tannins, total phenolics, polymeric pigments, and color particularly when this treatment was applied to unripe Merlot fruit harvested with 21.1 Brix. There was a lesser effect of MW on these same parameters on the wines made from ripe (23.1 Brix) and fully ripe (25.1 Brix) fruit, and when early improvements were observed, these generally disappeared during winemaking. In the case of fully ripe fruit, the application of MW caused negative effects in some phenolic compounds. This is consistent with the reported effect of similar heat-based techniques, such as thermomaceration or flash-détente, on red wines wherein early improvements in phenolics and color tend to subside after alcoholic fermentation.

The positive results observed upon application of MW to unripe fruit suggests that this technique furthers phenolic extraction in the case of fruit that may be deficient in phenolic maturity. As such, MW can become a valid tool to handle fruit that is either unripe or may be compromised by fungal or other diseases, as well as healthy fruit that may necessitate early harvest due to logistic reasons. In the latter case, application of MW would allow the production of highly colored wines of moderate or relative lower alcohol content. These results need to be validated for other varieties and viticultural conditions. The feasibility to scale up the MW technology to industrial scale for handling crushed grapes requires subsequent evaluation as well.

Supplementary Materials: Supplementary materials can be found at http:/ / www.mdpi.com/2311-5637/5/1/ $15 /$ s1.

Author Contributions: L.F.C. conceived the research, designed and performed the experiments, performed the statistical analysis, evaluated the results, and wrote the paper; S.E.S. performed the experiments, analyzed the samples, and evaluated the results; E.A.B. performed the experiments; M.L.F. analyzed the samples, performed the statistical analysis and evaluated the results. All the authors read and approved the final version of the manuscript. 
Funding: This research was funded by the Instituto Nacional de Tecnología Agropecuaria (INTA) Grant Number MZASJ-1251101. INTA is thanked for financial and logistical support of the project.

Acknowledgments: INTA personnel are thanked for help during harvest and winemaking. Vanesa Garcia is acknowledged for skillful analytical support.

Conflicts of Interest: The authors declare no conflict of interest.

\section{References}

1. Bindon, K.; Holt, H.; Williamson, P.O.; Varela, C.; Herderich, M.; Francis, I.L. Relationships between harvest time and wine composition in Vitis vinifera L. cv. Cabernet Sauvignon 2. Wine sensory properties and consumer preference. Food Chem. 2014, 154, 90-101. [CrossRef] [PubMed]

2. Casassa, L.F. Phenolic management in red wines: Investigation of the timing and severity of Regulated Deficit Irrigation (RDI), grape maturity and selected maceration conditions by HPLC-MS and sensory techniques. Ph.D. Thesis, Washington State University, Pullman, WA, USA, 2013.

3. Casassa, L.F.; Beaver, C.W.; Mireles, M.; Larsen, R.C.; Hopfer, H.; Heymann, H.; Harbertson, J.F. Influence of fruit maturity, maceration length, and ethanol amount on chemical and sensory properties of Merlot wines. Am. J. Enol. Vitic. 2013, 64, 437-449. [CrossRef]

4. Casassa, L.F.; Harbertson, J.F. Extraction, evolution, and sensory impact of phenolic compounds during red wine maceration. Annu. Rev. Food Sci. Technol. 2014, 5, 83-109. [CrossRef] [PubMed]

5. Adams, D.O. Phenolics and Ripening in Grape Berries. Am. J. Enol. Vitic. 2006, 57, 249-256.

6. Chen, J.-Y.; Wen, P.-F.; Kong, W.-F.; Pan, Q.-H.; Wan, S.-B.; Huang, W.-D. Changes and subcellular localizations of the enzymes involved in phenylpropanoid metabolism during grape berry development. J. Plant Physiol. 2006, 163, 115-127. [CrossRef] [PubMed]

7. Casassa, L.F. Flavonoid Phenolics in Red Winemaking. In Phenolic Compounds—Natural Sources, Importance and Applications; Soto-Hernandez, M., Palma-Tenango, M., Garcia-Mateos, M.d.R., Eds.; InTech: Rijeka, Croatia, 2017. [CrossRef]

8. Gil, M.; Kontoudakis, N.; González, E.; Esteruelas, M.; Fort, F.; Canals, J.M.; Zamora, F. Influence of Grape Maturity and Maceration Length on Color, Polyphenolic Composition, and Polysaccharide Content of Cabernet Sauvignon and Tempranillo Wines. J. Agric. Food Chem. 2012, 60, 7988-8001. [CrossRef]

9. Bindon, K.; Varela, C.; Kennedy, J.; Holt, H.; Herderich, M. Relationships between harvest time and wine composition in Vitis vinifera L. cv. Cabernet Sauvignon 1. Grape and wine chemistry. Food Chem. 2013, 138, 1696-1705. [CrossRef]

10. Setford, P.C.; Jeffery, D.W.; Grbin, P.R.; Muhlack, R.A. Factors affecting extraction and evolution of phenolic compounds during red wine maceration and the role of process modelling. Trends Food Sci. Technol. 2017, 69, 106-117. [CrossRef]

11. Koyama, K.; Goto-Yamamoto, N.; Hashizume, K. Influence of Maceration Temperature in Red Wine Vinification on Extraction of Phenolics from Berry Skins and Seeds of Grape (Vitis vinifera). Biosci. Biotechnol. Biochem. 2007, 71, 958-965. [CrossRef]

12. Doco, T.; Williams, P.; Cheynier, V. Effect of Flash Release and Pectinolytic Enzyme Treatments on Wine Polysaccharide Composition. J. Agric. Food Chem. 2007, 55, 6643-6649. [CrossRef]

13. Morel-Salmi, C.; Souquet, J.-M.; Bes, M.; Cheynier, V. Effect of Flash Release Treatment on Phenolic Extraction and Wine Composition. J. Agric. Food Chem. 2006, 54, 4270-4276. [CrossRef] [PubMed]

14. Aguilar, T.; Loyola, C.; de Bruijn, J.; Bustamante, L.; Vergara, C.; von Baer, D.; Mardones, C.; Serra, I. Effect of thermomaceration and enzymatic maceration on phenolic compounds of grape must enriched by grape pomace, vine leaves and canes. Eur. Food Res. Technol. 2016, 242, 1149-1158. [CrossRef]

15. Carew, A.L.; Gill, W.; Close, D.C.; Dambergs, R.G. Microwave Maceration with Early Pressing Improves Phenolics and Fermentation Kinetics in Pinot noir. Am. J. Enol. Vitic. 2014, 65, 401-406. [CrossRef]

16. Chandrasekaran, S.; Ramanathan, S.; Basak, T. Microwave food processing-A review. Food Res. Int. 2013, 52, 243-261. [CrossRef]

17. Casassa, L.F.; Huff, R.; Miller, E. Effect of Stem Additions and Microwave Extraction of Musts and Stems on Syrah, Merlot, and Cabernet Sauvignon Wines. In Proceedings of the 68th American Society for Enology and Viticulture National Conference, Seattle, WA, USA, 26-29 June 2017. 
18. Carew, A.L.; Sparrow, A.; Curtin, C.D.; Close, D.C.; Dambergs, R.G. Microwave Maceration of Pinot Noir Grape Must: Sanitation and Extraction Effects and Wine Phenolics Outcomes. Food Bioprocess Technol. 2013. [CrossRef]

19. Iland, P.; Bruer, N.; Edwards, G.; Caloghiris, S.; Wilkes, E. Chemical Analysis of Grapes and Wine Techniques and Concepts, 2nd ed.; Patrick Iland Wine Promotions Pty Ltd.: Adelaide, Australia, 2012; p. 118.

20. Glories, Y. La couleur des vins rouges. 2ème partie. Mesure, origine et interprétation. Connaissance de la Vigne et du Vin 1984, 18, 253-271.

21. Harbertson, J.F.; Picciotto, E.A.; Adams, D.O. Measurement of polymeric pigments in grape berry extracts and wines using a protein precipitation assay combined with bisulfite bleaching. Am. J. Enol. Vitic. 2003, 54, 301-306.

22. Blanco-Vega, D.; López-Bellido, F.J.; Alía-Robledo, J.M.; Hermosín-Gutiérrez, I. HPLC-DAD-ESI-MS/MS Characterization of Pyranoanthocyanins Pigments Formed in Model Wine. J. Agric. Food Chem. 2011, 59, 9523-9531. [CrossRef]

23. Rankine, B.C.; Bridson, D.A. Glycerol in Australian Wines and Factors Influencing Its Formation. Am. J. Enol. Vitic. 1971, 22, 6-12.

24. El Darra, N.; Turk, M.F.; Ducasse, M.-A.; Grimi, N.; Maroun, R.G.; Louka, N.; Vorobiev, E. Changes in polyphenol profiles and color composition of freshly fermented model wine due to pulsed electric field, enzymes and thermovinification pretreatments. Food Chem. 2016, 194, 944-950. [CrossRef]

25. de Andrade Neves, N.; de Araújo Pantoja, L.; dos Santos, A. Thermovinification of grapes from the Cabernet Sauvignon and Pinot Noir varieties using immobilized yeasts. Eur. Food Res. Technol. 2014, 238, 79-84. [CrossRef]

26. Robinson, S.P.; Davies, C. Molecular biology of grape berry ripening. Aust. J. Grape Wine Res. 2000, 6, 175-188. [CrossRef]

27. Garrido-Bañuelos, G.; Buica, A.; Schückel, J.; Zietsman, A.J.J.; Willats, W.G.T.; Moore, J.P.; Du Toit, W.J. Investigating the relationship between cell wall polysaccharide composition and the extractability of grape phenolic compounds into Shiraz wines. Part II: Extractability during fermentation into wines made from grapes of different ripeness levels. Food Chem. 2019, 278, 26-35. [CrossRef] [PubMed]

28. Hagerman, A.E.; Butler, L.G. The specificity of proanthocyanidin-protein interactions. J. Biol. Chem. 1981, 256, 4494-4497. [PubMed]

29. Peyrot des Gachons, C.; Kennedy, J.A. Direct Method for Determining Seed and Skin Proanthocyanidin Extraction into Red Wine. J. Agric. Food Chem. 2003, 51, 5877-5881. [CrossRef] [PubMed]

30. Harbertson, J.F.; Kennedy, J.A.; Adams, D.O. Tannin in skins and seeds of Cabernet Sauvignon, Syrah, and Pinot Noir berries during ripening. Am. J. Enol. Vitic. 2002, 53, 54-59.

31. Casassa, L.F.; Beaver, C.W.; Mireles, M.S.; Harbertson, J.F. Effect of extended maceration and ethanol concentration on the extraction and evolution of phenolics, colour components and sensory attributes of Merlot wines. Aust. J. Grape Wine Res. 2013, 19, 25-39. [CrossRef]

32. Harbertson, J.F.; Mireles, M.S.; Harwood, E.D.; Weller, K.M.; Ross, C.F. Chemical and sensory effects of saignée, water addition, and extended maceration on high Brix must. Am. J. Enol. Vitic. 2009, 60, 450-460.

33. Harbertson, J.F.; Spayd, S. Measuring Phenolics in the Winery. Am. J. Enol. Vitic. 2006, 57, 280-288.

34. Adams, D.O.; Harbertson, J.F.; Picciotto, E.A. Fractionation of red wine polymeric pigments by protein precipitation and bisulfite bleaching. In Red Wine Color; American Chemical Society: Washington, DC, USA, 2004; Vol. 886, pp. 275-288.

35. Garrido-Bañuelos, G.; Buica, A.; Schückel, J.; Zietsman, A.J.J.; Willats, W.G.T.; Moore, J.P.; Du Toit, W.J. Investigating the relationship between grape cell wall polysaccharide composition and the extractability of phenolic compounds into Shiraz wines. Part I: Vintage and ripeness effects. Food Chem. 2019, 278, 36-46. [CrossRef]

36. de Freitas, V.; Mateus, N. Formation of pyranoanthocyanins in red wines: A new and diverse class of anthocyanin derivatives. Anal. Bioanal. Chem. 2011, 401, 1463-1473. [CrossRef] [PubMed]

37. Fulcrand, H.; Dueñas, M.; Salas, E.; Cheynier, V. Phenolic Reactions during Winemaking and Aging. Am. J. Enol. Vitic. 2006, 57, 289-297.

(C) 2019 by the authors. Licensee MDPI, Basel, Switzerland. This article is an open access article distributed under the terms and conditions of the Creative Commons Attribution (CC BY) license (http:/ / creativecommons.org/licenses/by/4.0/). 